\title{
BMJ Open Adherence to guidelines on antibiotic treatment for respiratory tract infections in various categories of physicians: a retrospective cross-sectional study of data from electronic patient records
}

\author{
David Tell, ${ }^{1}$ Sven Engström, ${ }^{2}$ Sigvard Mölstad ${ }^{3}$
}

To cite: Tell D, Engström S, Mölstad S. Adherence to guidelines on antibiotic treatment for respiratory tract infections in various categories of physicians: a retrospective cross-sectional study of data from electronic patient records. BMJ Open 2015;5:e008096

doi:10.1136/bmjopen-2015008096

- Prepublication history for this paper is available online. To view these files please visit the journal online (http://dx.doi.org/10.1136/ bmjopen-2015-008096).

Received 3 March 2015 Revised 21 May 2015 Accepted 22 June 2015

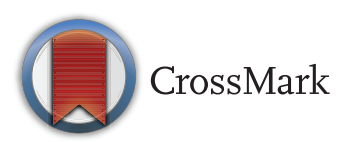

${ }^{1}$ Råslätt Health Care Centre, Jönköping, Sweden

${ }^{2}$ Primary Care Research and Development Unit, Futurum, Jönköping, Sweden ${ }^{3}$ Department of Clinical Sciences, General Practice, Lund University, Lund, Sweden

Correspondence to Dr David Tell; david.tell@rlj.se
ABSTRACT

Objective: To study how prescription patterns concerning respiratory tract infections differ between interns, residents, younger general practitioners (GPs), older GPs and locums.

Design: Retrospective study of structured data from electronic patient records.

Setting: Data were obtained from 53 health centres and 3 out-of-hours units in Jönköping County, Sweden, through their common electronic medical record database.

Participants: All physicians working in primary care during the 2-year study period (1 November 2010 to 31 October 2012).

Outcome measures: Physicians' adherence to current guidelines for respiratory tract infections regarding the use of antibiotics.

Results: We found considerable differences in prescribing patterns between physician categories. The recommended antibiotic, phenoxymethylpenicillin, was more often prescribed by interns, residents and younger GPs, while older GPs and locums to a higher degree prescribed broad-spectrum antibiotics. The greatest differences were seen when the recommendation in guidelines was to refrain from antibiotics, as for acute bronchitis. Interns and residents most often followed guidelines, while compliance in descending order was: young GPs, older GPs and locums. We also noticed that male doctors were somewhat overall more restrictive with antibiotics than female doctors.

Conclusions: In general, primary care doctors followed national guidelines on choice of antibiotics when treating respiratory tract infections in children but to a lesser degree when treating adults. Refraining from antibiotics seems harder. Adherence to national guidelines could be improved, especially for acute bronchitis and pneumonia. This was especially true for older GPs and locums whose prescription patterns were distant from the prevailing guidelines.

\section{BACKGROUND}

Bacterial resistance is a growing problem and a subject of international concern. ${ }^{12}$ It is

\section{Strengths and limitations of this study}

- The study covers every healthcare centre in Jönköping county.

- The analyses of prescribing patterns comparing physician categories cover $88 \%$ of all consultations.

- The study includes a large number of doctors in all physician categories, and a very large number of visits.

- The study is based on retrieval of structured data from electronic patient records. The assessment of adherence to guidelines may often require facts that are recorded in plain text. These could not be retrieved from the database.

related to consumption of antibiotics by the individual and in the community, as well as to the types of antibiotics consumed. ${ }^{3}{ }^{4}$ In Europe, the prescription for antibiotics differs between countries, and antibiotics are prescribed significantly more often in southern compared to northern Europe. ${ }^{5}$ Sweden is one of the countries with low prescribing, but the prescription rate varies greatly between counties. ${ }^{6-9}$ No obvious medical explanation for this variation exists. Respiratory tract infections (RTIs), including acute otitis media, are the most common reasons for consultations in general practice and for antibiotic treatment. ${ }^{10}$ In Sweden, there are national guidelines for all infections common in primary care. Phenoxymethylpenicillin $(\mathrm{PcV})$ is the recommended first choice in antibiotics for acute otitis media, ${ }^{11}$ sinusitis, ${ }^{12}$ tonsillitis ${ }^{13}$ and pneumonia. ${ }^{14}$ No antibiotic treatment is recommended for acute bronchitis. ${ }^{14}$

In Sweden, medical education begins with five-and-a-half years of university studies, leading to a Master of Science in Medicine. Following this, the National board of Health and Welfare requires a minimum of 
18 months of clinical internship (interns) before granting a medical licence as a fully qualified Doctor of Medicine. ${ }^{15}$ On receiving a licence to practise, a physician is able to apply for a post to start specialist training (residents). Specialist training to become a general practitioner (GP) requires at least 5 years of full-time work.

In autumn 2012, there were 4784 GPs in Swedish primary care. A survey study showed that 1863 resident doctors were employed in primary care of which one-third temporarily served at another clinic as part of their specialist training. ${ }^{16}$ Since there is a shortage of GPs in Sweden, locums are employed for shorter or longer periods and, according to the same survey, 949 locum doctors served in primary care during autumn 2012 on an ordinary Tuesday. The main part of the locums, $71 \%$, were fully trained GPs, and $20 \%$ had not yet acquired any specialty.

Electronic patient records (EPR), with a search-termbased structure and possibilities for data retrieval, offer opportunities to study clinical data registered in daily practise. ${ }^{17}$ EPRs are currently used by almost all GPs in Sweden, providing clinical data that are useful for research. Primary care accounts for the majority of outpatient antibiotic prescribing. Large differences in antibiotic prescribing patterns have been observed between GPs, ${ }^{18}$ but the causes for these differences are not fully understood. Smaller US studies have found that residents follow guidelines better than do their supervisors, ${ }^{19}$ and that the longer the education proceeds, the more the training physicians assume the prescribing patterns of their supervisors. ${ }^{20}$ To our knowledge, there are no studies published on variations in authentic prescription patterns between different categories of physicians in primary care.

The objective of this study was to study how the prescription patterns concerning lower respiratory tract infections (LRTIs) differ between interns, residents, younger GPs, older GPs and locums.

\section{MATERIAL AND METHODS}

Jönköping County is 1 of 20 counties in Sweden. In November 2010, the population of the county was 336527 , served by 53 primary healthcare centres (PHCCs) and three out-of-hours units. All healthcare units in Jönköping County used the same electronic medical record system (Cambio Cosmic). More than $95 \%$ of all consultations were labelled with an International Classification of Diseases (ICD) 10 diagnostic code. The following data were retrieved from all consultations in primary care with an infection diagnosis: date of consultation, age, gender, diagnosis, any prescribed antibiotic (ATC code), name of physician and PHCC. The study period covered 2 years, from 1 November 2010 to 31 October 2012.

Individual diagnoses were analysed based on the diagnostic codes in the material. We chose to analyse the following diagnostic areas: RTIs, acute bronchitis (in patients younger than 50 years) and pneumonia. The age limit for acute bronchitis was set because it was not clear which treatment was recommended for the elderly in previous national guidelines. To reduce disturbance of varying diagnostic labelling between physicians, we also studied LRTIs overall by aggregating the diagnoses acute bronchitis, pneumonia and cough.

Prescribing physicians were divided into five different groups: interns, resident doctors, younger GPs, older GPs and locums. The employment status, age and gender were obtained from the Jönköping county council personnel department and the principal for the interns. The categorisation between older and younger GPs was based on the median age for the GPs: 53 years.

Physicians with less than 100 consultations during the 2-year study period were excluded from the analyses of adherence to guidelines for LRTIs. In cases where a physician changed employment status during the study period, the physician was categorised after the last employment form.

Data were processed and analysed in Excel 2007 and SPSS V.20.0.0. Significances were tested with the $\chi^{2}$ test. Owing to the very large number of observations, reported differences were highly significant $(p<0.001)$ and $p$ values are, therefore, not reported.

\section{Ethics}

Confidentiality for patients was ensured by one-way encrypted ID-numbers. The identity of the physicians was only used to group the physicians to any of the studied medical categories. No analyses were performed for individual physician performance. The study was approved by the Regional Ethics Review Board in Linköping.

\section{RESULTS}

During the study period, 1 November 2010 to 31 October 2012, a total of 264810 consultations labelled with an infection diagnostic code were registered. In total, 753 prescribers of antibiotics were identified and categorised (table 1). The categorised physicians accounted for $88 \%$ (232 922) of all consultations.

Table 1 Numbers of physicians in the different categories, number of consultations and patient age

\begin{tabular}{lccl}
\hline $\begin{array}{l}\text { Category of } \\
\text { physician }\end{array}$ & $\begin{array}{l}\text { Physicians } \\
(\mathbf{n})\end{array}$ & $\begin{array}{l}\text { Consultations } \\
(\mathbf{n})\end{array}$ & $\begin{array}{l}\text { Patients } \\
\text { mean age } \\
\text { and (SD) }\end{array}$ \\
\hline $\begin{array}{l}\text { Interns } \\
\text { Residents }\end{array}$ & 84 & 17642 & $35.8(25.1)$ \\
$\begin{array}{l}\text { Younger GPs } \\
(<53 \text { years) }\end{array}$ & 86 & 29520 & $37.0(26.3)$ \\
$\begin{array}{l}\text { Older GPs } \\
\text { ( } \geq 53 \text { years) }\end{array}$ & 126 & 65134 & $40.0(27.0)$ \\
$\begin{array}{l}\text { Locums } \\
\text { Uncategorised } \\
\text { physician }\end{array}$ & 113 & 87689 & $41.4(27.2)$ \\
Total & 275 & 32937 & $37.6(26.4)$ \\
\hline & 753 & 264810 & \\
\hline
\end{tabular}


We were able to define the gender of 427 physicians. The proportions of females among the interns were $58 \%$, residents $55 \%$, younger GPs $54 \%$, older GPs $30 \%$ and locums $22 \%$.

Of all consultations, $65 \%$ were labelled as RTIs or ear infections (table 2). These diagnoses accounted for $56 \%$ of all antibiotic prescriptions during the study period.

During the study period, a total of 172546 consultations with a diagnosis of RTI or ear infection were registered corresponding to 256 consultations/1000 inhabitants per 12 month period. The categorised physicians accounted for 150892 of the consultations (table 2). The proportion of consultations for RTIs and ear infections that included an antibiotic prescription varied between the categories of physicians: interns 33\%, residents 35\%, younger GPs 33\%, older GPs 36\% and locums $46 \%$. The prescribing of the recommended antibiotic for RTIs and ear infections (PcV) diverged between categories of physicians. The highest proportion of $\mathrm{PcV}$ was prescribed by interns $(70 \%)$ and residents $(72 \%)$, while younger GPs $(66 \%)$, older GPs $(62 \%)$ and locum doctors $(60 \%)$ to a higher degree chose broad-spectrum antibiotics. A similar pattern was seen in the prescribing for RTIs in children 0-6 years. The proportions of $\mathrm{PcV}$ were: for interns $(86 \%)$, residents $(84 \%)$, younger GPs $(82 \%)$, older GPs $(81 \%)$ and locums $(78 \%)$.

The prescription patterns for LRTIs varied between categories of physicians, with the greatest differences concerning acute bronchitis. The interns prescribed an antibiotic in $18 \%$ of cases with acute bronchitis, while locums prescribed an antibiotic to $56 \%$ of patients with

Table 2 Number of categorised physician consultations (n), proportion (\%) prescribed antibiotic and proportion (\%) PcV for RTI diagnoses and ear infections during the study period (1 November 2010 to 31 October 2012)

\begin{tabular}{lccc}
\hline & (n) & $\begin{array}{c}\text { Percentage } \\
\text { prescribed } \\
\text { antibiotics }\end{array}$ & $\begin{array}{l}\text { Percentage } \\
\text { PcV of all } \\
\text { antibiotics }\end{array}$ \\
\hline Common cold & 36261 & 7.3 & 49 \\
Tonsillitis & 17188 & 88.3 & 86 \\
Chronic & 15440 & 12.3 & 4 \\
obstructive & & & \\
pulmonary & & & \\
disease* & & & 28 \\
Acute bronchitis & 13967 & 33.9 & 46 \\
Pneumonia & 13415 & 73.4 & 84 \\
Acute otitis media & 13109 & 81.1 & 25 \\
Cough & 12176 & 4.6 & 70 \\
Sinusitis & 9031 & 73.3 & 62 \\
Otitis externa & 8052 & 12.6 & 77 \\
Pharyngitis & 4696 & 18.5 & 68 \\
Other & 7557 & 10.4 & 65 \\
Total & 150892 & 36.3 & \\
*Only a few cases were labelled acute exacerbations of COPD. \\
COPD, chronic obstructive pulmonary disease; PcV, \\
phenoxymethylpenicillin; RTI, respiratory tract infection.
\end{tabular}

this diagnosis. When analysing LRTIs overall, by aggregating the diagnoses to acute bronchitis, pneumonia and cough, we still found great differences between different categories of physicians (table 3 ).

Female physicians showed a higher prescription rate of antibiotics for RTIs, 39\% of cases compared with male physicians, $34 \%$. Male interns had the lowest proportion of prescriptions, $29 \%$, while the highest prescribing rate, $51 \%$, was found among female locums. For acute bronchitis in patients $<50$ years, female physicians prescribed an antibiotic in $35 \%$ of cases compared with male physicians, 25\%.There were, however, no differences in the choice of antibiotic for RTIs in total, females prescribed $\mathrm{PcV}$ in $66 \%$ of cases with antibiotics and males in $65 \%$ of cases.

\section{DISCUSSION}

In our study, we found considerable differences in prescribing patterns between physician categories. The greatest differences were seen in acute bronchitis, where guidelines recommended avoidance of antibiotics. Interns and residents most often followed guidelines, while compliance in descending order was: younger GPs, older GPs and locums. The differences in prescribing were still evident although less pronounced, regarding the entire diagnostic group, LRTIs (acute bronchitis, pneumonia and cough).We also noted that male doctors were, overall, somewhat more restrictive with antibiotics than female doctors.

The main weakness of the study is that it is retrospective and based on retrieval of structured data from the EPR. The assessment of adherence to guidelines often requires facts that are recorded in plain text, such as patient history, clinical signs, severity of infection, patient's socioeconomic status and utilisation of rapid tests, which could not be retrieved from the database. We have chosen to study antibiotic prescriptions for LRTIs since they are more suitable for evaluation of adherence to guidelines by data retrieval than upper RTIs. We assumed that by collecting a large number of visits, the effect of exceptions would diminish and the customary procedures dominate. In all physician categories, there were a large number of physicians and a very large number of visits. Studies have shown that the selection of diagnoses may vary between physicians ${ }^{21}$ which may influence the frequency of antibiotic prescribing. ${ }^{22}$ We adjusted for this by also analysing LRTIs in total. We choose also to include the symptom diagnosis cough, to make sure that all diagnoses that might represent a LRTI was accounted for.

Further, a high number of antibiotic prescriptions (31\% of all prescriptions in 2011 and $25 \%$ in 2012) were found in consultations without an infection diagnosis. Some of these cases could probably be explained by a missing ICD code. In some health centres, mild cases of respiratory and urinary tract infections are primarily assessed by nurses, and if antibiotics are then prescribed 
Table 3 Physician category, number of consultations (n), proportion (\%) prescribed antibiotic and percentage prescribed penicillin $\mathrm{V}$ for pneumonia and acute bronchitis (patients $<50$ years)

\begin{tabular}{|c|c|c|c|c|c|}
\hline & Interns & Residents & Younger GPs ( $<53$ years) & Older GPs ( $\geq 53$ years) & Locums \\
\hline \multicolumn{6}{|l|}{ Pneumonia } \\
\hline (n) & 1003 & 1613 & 3974 & 4887 & 1938 \\
\hline Percentage prescribed antibiotics & 82.9 & 77.2 & 72.5 & 68.3 & 80.1 \\
\hline Percentage PcV of antibiotics & 47.9 & 50.3 & 48.6 & 45 & 39.8 \\
\hline \multicolumn{6}{|c|}{ Acute bronchitis patients $<50$ years } \\
\hline (n) & 566 & 813 & 2042 & 3058 & 793 \\
\hline Percentage prescribed antibiotics & 17.8 & 15.9 & 19.1 & 35.2 & 56.4 \\
\hline Percentage PcV of antibiotics & 19.8 & 53.5 & 37.6 & 34.6 & 33.8 \\
\hline \multicolumn{6}{|l|}{ Cough } \\
\hline (n) & 1292 & 1469 & 3333 & 4109 & 1973 \\
\hline Percentage prescribed antibiotics & 2.9 & 4.6 & 3.7 & 4.4 & 7.9 \\
\hline Percentage PcV of antibiotics & 28.9 & 23.9 & 30.1 & 24.7 & 20.5 \\
\hline \multicolumn{6}{|l|}{ LRTIs overall } \\
\hline (n) & 2861 & 3895 & 9349 & 12054 & 4704 \\
\hline Percentage prescribed antibiotics & 32.3 & 36 & 35.3 & 38.9 & 48.4 \\
\hline Percentage PcV of antibiotics & 42.2 & 46.8 & 43.6 & 37.6 & 33.9 \\
\hline
\end{tabular}

by a physician, the diagnostic code is not always recorded. Antibiotics are sometimes prescribed after test results have arrived, or after patients reporting worsening symptoms, maybe a few days after the initial visit, this time often with no recording of ICD code. Furthermore, antibiotics are, in many cases, prescribed to patients with chronic disease, without documentation of actual symptoms. For these prescriptions, without an infection diagnosis, adherence to guidelines could not be studied.

A strength of this study is that the same EPR system is used by every PHCC, including all physicians in primary care, in the county. All consultations with infection diagnoses during the 2-year study period, and thus, a very large number of observations, could be retrieved. In addition, the analyses of prescribing patterns between physician categories cover $88 \%$ of all consultations in the database. The missing $12 \%$ consists of 275 prescribers with less than 100 consultations during the 2-year study period. It is likely that the majority of these prescribers consist of locums who only worked shorter periods in the county.

This study showed that adherence to the Swedish guidelines for antibiotic use can be improved, especially for acute bronchitis, since $29 \%$ of patients younger than 50 years presenting with acute bronchitis were prescribed antibiotics, despite solid evidence that only few may benefit from antibiotics. However, this might represent a positive trend since a recent (2010) Swedish study, including patients of all ages showed antibiotic prescription in $45 \%$ of patients with acute bronchitis. ${ }^{10}$

The spread between different groups of physicians was great. Interns, residents and younger GPs reached the national goal of less than $20 \%$ of antibiotic use in acute bronchitis, while older GPs and locums treated acute bronchitis in $35 \%$ and $56 \%$ of cases, respectively. The high prescribing among older GPs is probably due to the fact that older GPs still applied former traditions of treating acute bronchitis with antibiotics, while younger colleagues have learned to act according to current guidelines. Recommendations to refrain from antibiotics in acute bronchitis have, however, been around for more than 10 years, and it is obvious that new methods are needed to encourage older GPs to change their prescribing habits. Our findings are in line with other studies showing that physician age and years in practice both have a positive correlation with the rate of antibiotic prescriptions. ${ }^{23}$

Why locums to such a large extent prescribed antibiotics to $56 \%$ of patients with acute bronchitis, might be due to several factors. Locums, probably, have a generally tighter schedule than a permanent GP. A stressed physician may feel that it is time consuming to discuss alternative approaches with the patient, and therefore chooses to prescribe antibiotics instead. However, we found that at the county's out-of-hours centres with very high consultation rates, only $25 \%$ of patients with acute bronchitis were treated with antibiotics. One explanation for the higher prescription rate among locums may be that they, to a lesser degree, are up to date on current guidelines. Locums are rarely involved in internal meetings, do not have the same opportunity for professional development, often change workplace and, consequently, are not given the opportunity to receive feedback on their prescribing patterns. There is probably also a risk that a temporary physician does not feel the same responsibility as a permanent physician for the listed population of the healthcare centre, and the negative effects of antibiotics on resistance levels. We considered that locums may more often serve at PHCCs in areas with low socioeconomic status, which could thus explain a higher need for antibiotics. However, at PHCC-level, locums performed the same proportion of consultations in affluent as in deprived areas. 
In Swedish primary care, patients most often call their PHCC to get an appointment. Specialised nurses will evaluate history and symptoms and most patients with mild symptoms receive telephone advice from the nurse and not a physician consultation. This triage system can explain the low prevalence of consultations per inhabitant for RTIs and especially for the diagnoses common cold, pharyngitis and acute bronchitis.

Previous studies have shown that physicians choose diagnoses motivating their choice of treatment, ${ }^{22}$ and we noted a rather high number of consultations for pneumonias in our study, 20 per 1000 inhabitants, of which only approximately $75 \%$ received an antibiotic prescription. This indicates that about one-quarter of these consultations were control visits, since antibiotics are always recommended for pneumonia.

In our study, there were differences in antibiotic prescription rates between male and female physicians, but not in the choice of antibiotic. Lopez-Vazquez et al performed a thorough literature review of physician characteristics influencing antibiotic prescribing. Most of the studies included in this systematic review did not find any influence of the GP's gender in antibiotic prescription. They concluded, however, that 'most of the studies used fictitious cases posed on a questionnaire in order to simulate prescribing'. ${ }^{23}$ The reasons for differences in prescribing patterns between genders need to be studied more closely.

\section{CONCLUSION}

In general, primary care doctors choose antibiotics $(\mathrm{PcV})$ according to national guidelines for respiratory infections in children, and also, although to a somewhat lesser degree, in adults. Refraining from antibiotic treatment in acute bronchitis seems to be more difficult. Concerns about complications seem to outweigh individual side effects and spread of antibiotic resistance. Adherence to national guidelines should be improved, especially for common respiratory infections such as acute bronchitis and pneumonia. This is especially true for older GPs and, in particular, for locums whose prescription patterns were distant from the prevailing guidelines. New methods are needed to encourage these groups of physicians to change their behaviour.

Contributors DT and SE participated actively in study design, acquisition of the data, data analyses and drafted the work. SM participated in drafting, data evaluation and finalising the manuscript. All authors have read and approved the final manuscript.

Funding This work was supported by grants from Futurum, County Council of Jönköping, Sweden.

Competing interests None declared.

Ethics approval Regional Ethics Review Board in Linköping.

Provenance and peer review Not commissioned; externally peer reviewed.

Data sharing statement The study data are available from DT and SE.

Open Access This is an Open Access article distributed in accordance with the Creative Commons Attribution Non Commercial (CC BY-NC 4.0) license, which permits others to distribute, remix, adapt, build upon this work noncommercially, and license their derivative works on different terms, provided the original work is properly cited and the use is non-commercial. See: http:// creativecommons.org/licenses/by-nc/4.0/

\section{REFERENCES}

1. World Health Organization. Antimicrobial resistance: global report on surveillance 2014. World Health Organization, 2014.

2. Bronzwaer S, Lonnroth A, Haigh R. The European Community strategy against antimicrobial resistance. Euro Surveill 2004;9:30-4.

3. van de Sande-Bruinsma N, Grundmann H, Verloo D, et al. Antimicrobial drug use and resistance in Europe. Emerg Infect Dis 2008;14:1722-30.

4. Bronzwaer SL, Cars O, Buchholz U, et al. A European study on the relationship between antimicrobial use and antimicrobial resistance. Emerg Infect Dis 2002;8:278-82.

5. Molstad S, Lundborg CS, Karlsson AK, et al. Antibiotic prescription rates vary markedly between 13 European countries. Scand J Infect Dis 2002;34:366-71.

6. Hedin K, Andre M, Hakansson A, et al. A population-based study of different antibiotic prescribing in different areas. $\mathrm{Br} J$ Gen Pract 2006;56:680-5.

7. Folkhälsomyndigheten. SWEDRES-SVARM 2013. Stockholm, 2014:115. http://www.folkhalsomyndigheten.se/publicerat-material/ publikationer/Swedres-Svarm-2013/

8. Molstad S, Erntell M, Hanberger $\mathrm{H}$, et al. Sustained reduction of antibiotic use and low bacterial resistance: 10-year follow-up of the Swedish Strama programme. Lancet Infect Dis 2008;8:125-32.

9. Adriaenssens N, Coenen S, Versporten A, et al. European Surveillance of Antimicrobial Consumption (ESAC): outpatient antibiotic use in Europe (1997-2009). J Antimicrob Chemother 2011;66(Suppl 6):vi3-12.

10. Nord M, Engstrom S, Molstad S. High and variable use of antibiotics in primary care.(Hög och varierande förskrivning av antibiotika i primärvården). Lakartidningen 2013;110:1282-4.

11. Medical Products Agency. Diagnosis, treatment and follow-up of acute otitis media (Diagnostik, behandling och uppföljning av akut mediaotit) Information från Läkemedelsverket. Stockholm: Medical Products Agency, Sweden (Läkemedelsverket), 2010:13-21.

12. Medical Products Agency. Medical treatment of rhinosinusitis (Läkemedelsbehandling av rinosinuit). Information från Läkemedelsverket. Stockholm: Medical Products Agency, Sweden (Läkemedelsverket), 2005:7-48.

13. Medical Products Agency. Management of faryngotonsillitis (Handläggning av faryngotonsilliter in swedish). Information från Läkemedelsverket. Stockholm: Medical Products Agency, Sweden (Läkemedelsverket), 2012:18-25.

14. Medical Products Agency. Medical treatment of lower airway infections (Farmakologisk behandling av nedre luftvägsinfektioner) Information från Läkemedelsverket. Stockholm: Medical Products Agency, Sweden (Läkemedelsverket), 2008:7-72.

15. The National Board of Health and Welfare. Regulations and general advice about doctors' specialist training (Socialstyrelsens föreskrifter och allmänna råd om läkarnas specialiseringstjänstgöring). Stockholm: Socialstyrelsen, 2014

16. Svante P, Åsa J. Medical Association survey of primary care staffing (Läkarförbundets undersökning av primärvårdens bemanning). Stockholm: Läkarförbundet, 2013.

17. Engstrom S, Molstad S, Nilsson G, et al. Data from electronic patient records are suitable for surveillance of antibiotic prescriptions for respiratory tract infections in primary health care. Scand J Infect Dis 2004;36:139-43.

18. Gjelstad S, Dalen I, Lindbaek M. GPs' antibiotic prescription patterns for respiratory tract infections-still room for improvement. Scand J Prim Health Care 2009;27:208-15.

19. Mincey BA, Parkulo MA. Antibiotic prescribing practices in a teaching clinic: comparison of resident and staff physicians. South Med J 2001;94:365-9.

20. Robinson JD, Curry RW Jr, Dallman JJ, et al. Antibiotic prescribing in a family medicine residency program. J Fam Pract 1982;15:111-17.

21. Stausberg J, Lehmann N, Kaczmarek D, et al. Reliability of diagnoses coding with ICD-10. Int J Med Inform 2008;77:50-7.

22. Hutchinson JM, Jelinski S, Hefferton D, et al. Role of diagnostic labeling in antibiotic prescription. Can Fam Physician 2001;47:1217-24.

23. Lopez-Vazquez P, Vazquez-Lago JM, Figueiras A. Misprescription of antibiotics in primary care: a critical systematic review of its determinants. J Eval Clin Pract 2012;18:473-84. 